\title{
Elastoplastical Analysis of the Interface between Clay and Concrete Incorporating the Effect of the Normal Stress History
}

\author{
Zhao Cheng, Zhao Chunfeng, and Gong Hui \\ Key Laboratory of Geotechnical and Underground Engineering of Ministry of Education, Department of Geotechnical Engineering, \\ Tongji University, Shanghai 200092, China
}

Correspondence should be addressed to Zhao Chunfeng; structure.zhao@gmail.com

Received 8 June 2013; Revised 23 August 2013; Accepted 10 September 2013

Academic Editor: Ga Zhang

Copyright (c) 2013 Zhao Cheng et al. This is an open access article distributed under the Creative Commons Attribution License, which permits unrestricted use, distribution, and reproduction in any medium, provided the original work is properly cited.

The behaviour of the soil-structure interface is crucial to the design of a pile foundation. Radial unloading occurs during the process of hole boring and concrete curing, which will affect the load transfer rule of the pile-soil interface. Through large shear tests on the interface between clay and concrete, it can be concluded that the normal stress history significantly influences the shear behaviour of the interface. The numerical simulation of the bored shaft-soil interaction problem requires proper modelling of the interface. By taking the energy accumulated on the interface as a hardening parameter and viewing the shearing process of the interface as the process of the energy dissipated to do work, considering the influence of the normal stress history on the shearing rigidity, a mechanical model of the interface between clay and concrete is proposed. The methods to define the model parameters are also introduced. The model is based on a legible mathematical theory, and all its parameters have definite physical meaning. The model was validated using data from a direct shear test; the validation results indicated that the model can reproduce and predict the mechanical behaviour of the interface between clay and concrete under an arbitrary stress history.

\section{Introduction}

The bearing behaviour of geotechnical structures embedded in soil, such as deep foundations, tunnels, and retaining structures, is influenced by the contact behaviour at the interface between the surface of the structure and the surrounding soil. A systematic understanding of the shearing behaviour will enable a more accurate analysis and improve the ability to design these structures more accurately. The mechanism that transfers the load through the interface to the surrounding soil has received significant attention in the literature. Over recent decades, many constitutive models have been developed for the soil-structure interface, such as the hyperbolic model and the extended hyperbolic model $[1,2]$, the Ramberg-Osgood nonlinear elastic model [3], the directionally dependent constitutive model [4], the rate-type model [5], the elastoplastic model [6], and the damage model [7].

A series of shear tests on soil-concrete interfaces were performed using the independent developed visual large scale direct shear apparatus by G. A. Zhang and J. M. Zhang
$[8,9]$, by using that, the interface behaviour is visible with matching image measurement [10]. Evgin and Fakharian also developed the interface apparatus with the name of C3DSSI to carry out the two-way cyclic tangential-displacementcontrolled tests and cyclic rotational tests [11]. In geotechnical engineering, the pre- and postconstruction stress paths followed by the interface may be complex, as well as the unloading and reloading. Gómez et al. evaluated the effect of the unloading-reloading paths on the shear behaviour at the sand-concrete interface [12]. By analysing the test data of the groups of staged shear, unload-reload and multidirectional stress path tests, a four-parameter extended hyperbolic model was developed to account for the complex stress paths. However, there are no tests or models for the clay-concrete interface found in the literature that can consider the effect of the stress path; thus, there is a need for more investigation, although it may be more sensitive to stress history. Therefore, it is urgent to develop a model that can incorporate the influence of normal stress history.

In this study, a large direct test apparatus was used to study the clay-concrete interface. The model of the interface 
TABLE 1: Main properties of clay.

\begin{tabular}{lcccc}
\hline Water content & Plastic limit & Liquid limit & Cohesion & Internal friction angle \\
$\omega$ & $\omega_{p}$ & $\omega_{l}$ & $c(\mathrm{kPa})$ & $\varphi\left({ }^{\circ}\right)$ \\
\hline $30 \%$ & $22.4 \%$ & $45.6 \%$ & 11.5 & 22.3 \\
\hline
\end{tabular}

between clay and concrete is proposed, followed by the definition of the parameters in the model. Finally, the model was validated by a comparison with the results from the direct tests.

\section{Large Direct Test}

2.1. Test Apparatus. Despite some inherent problems, the direct shear apparatus is a commonly used device for interface testing because of its simplicity in sample preparation procedures and its suitability for interface testing. Therefore, a large displacement direct shear test machine in Tongji University was used to conduct the shear strength test on the soilconcrete interface. Compared to conventional direct shear box devices, the large displacement direct shear test results in more accurate interface shear measurements because the proportion of the overall interface affected by the boundaries is smaller for large devices than for smaller ones [13].

2.2. Soil Specimen. The soil specimen was remoulded clay. The main properties of the soil are listed in Table 1. The clay ash was acquired thorough the procedure of airing, crushing, and screening through a sieve (pore size of $0.05 \mathrm{~mm}$ ). To achieve the desired water content of $30 \%$, appropriately selected amounts of clay ash were thoroughly mixed with calculated amounts of water. Prior to being placed in the shear box, the mixture was left to cure for a period of 12 hours to ensure even water content in the specimen.

2.3. Concrete Plate Specimen. Ruled surface patterns were used to model the concrete surface in this study. The asperity height was changed to quantify the surface roughness, while the asperity angle was altered with the asperity height; the span of the sawtooth was zero in the tests. The asperity heights of the concrete samples were 0,10 , and $20 \mathrm{~mm}$, with asperity angles of 0,21.8 and 38.66 degrees, respectively. In the analysis, samples number $0, \# 1$, and \#2 represent the concrete plates with a sawtooth height of 0,10 , and $20 \mathrm{~mm}$, respectively.

The concrete specimen for testing was $600 \mathrm{~mm}$ long by $400 \mathrm{~mm}$ wide by $50 \mathrm{~mm}$ thick, as illustrated in Figure 1. The specimen was poured against plywood to produce the ruled surface. A wooden frame was attached along the plywood. After the specimen was poured, it was left to cure for 28 days to attain a standard strength. Subsequently, the wooden frame and plywood were removed.

2.4. Test Procedures. The prepared specimens were installed in the shear box in such a way that the bottom half contained the concrete plate, while the top half contained the soil. The interface between the soil and concrete was located exactly between the two halves of the shear box, as shown in Figure 2,

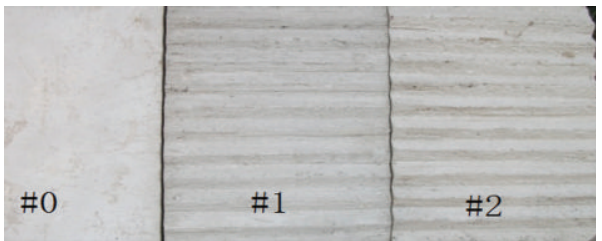

Figure 1: The topography of the concrete plate in the test.

to investigate the effect of the normal stress history and the degree of unloading on the shear behaviour and strength at the soil-concrete interface. The specimens were consolidated under an initial normal stress $\sigma_{n i}$ of 400,300 , and $200 \mathrm{kPa}$ for 1 hour, then unloaded to a specified normal stress $(50 \mathrm{kPa}$ to $350 \mathrm{kPa}$ ). Both of the loading and unloading rates are $1 \mathrm{KPa} / \mathrm{min}$. After 1 hour of being under a constant applied normal stress, the interface was sheared at a constant rate while the results were monitored. The normal load acting on the interface remained constant during the shear process. Each test was conducted with a rate of shear deformation of $0.3 \mathrm{~mm} / \mathrm{min}$ to a total of $30 \mathrm{~mm}$. This rate is sufficiently slow to ensure that the excess pore water pressures of the specimens are dissipated during the shearing. The $30 \mathrm{~mm}$ displacement criterion was selected because it was observed that under operational conditions, the accumulation of $30 \mathrm{~mm}$ of lateral displacement could result in excessive leakage of soil. All data regarding the test (horizontal shear force, shear, and normal displacement) were collected by a computerised data logging system. The results were monitored and saved using the computer software TEST.

\subsection{Test Results}

2.5.1. Effect of the Applied Normal Stress. Figure 3 shows typical test results for the interaction between clay and concrete plate $\# 0$ with an identical initial normal stress of $\sigma_{n i}=400 \mathrm{kPa}$. The data from the direct shear tests performed on the interface between clay and concrete plates $\# 1$ and \#2 are presented in Figures 4 and 5 for comparison. At the beginning of shearing, the shear stress increases sharply with the horizontal displacement. For the applied normal stresses of $50 \mathrm{kPa}$ and $100 \mathrm{kPa}$, as shear progresses, the stressstrain curves gradually trend to be flatter as the shear stress remains approximately constant for any further increment in the horizontal displacement. However, for other higher normal stresses, the shear stress increases relatively slowly with horizontal displacement in the later-shearing phase, and no strain-softening phenomenon is observed in the tests, which agrees with the results observed by Nasir and Fall [14]. From Figures 3, 4, and 5, it is also observed that the higher applied normal stress during shearing offers a shear 

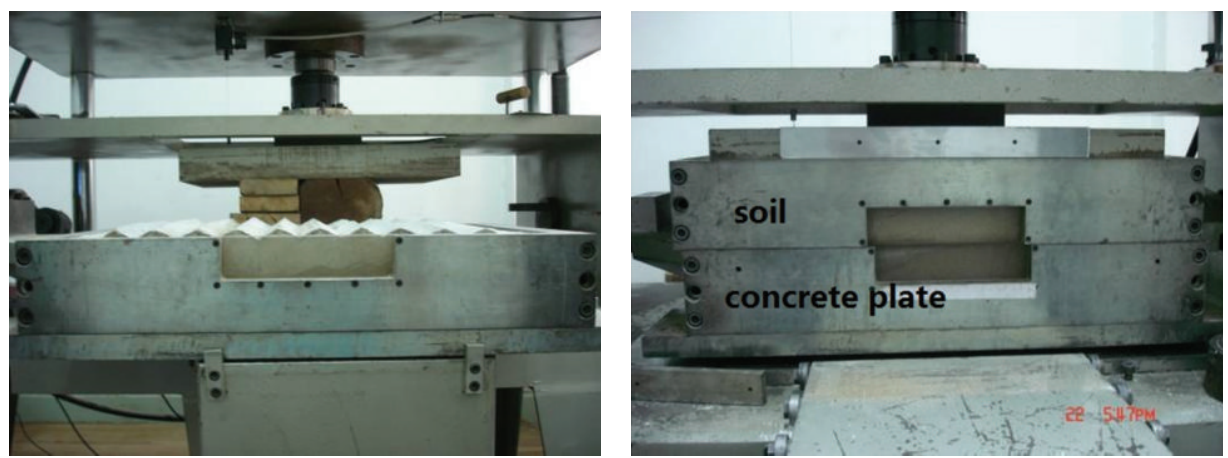

FIGURE 2: Setup of the specimen box.

stiffness increase for all the values of horizontal displacement. In the meantime, a dilative phenomenon was observed during the tests. Figures 3, 4, and 5 also exhibit this dilative behaviour for the interface between the clay and concrete plates. Before the dilation, the dilative force must offset the applied normal stress acting on the soil specimen, so the more significant dilative displacement was observed in the tests in which a lower normal stress was applied. For the highest applied normal stress of $350 \mathrm{kPa}$, the clay-concrete interface first exhibits a short contracting behaviour followed by dilatation. The contracting behaviour can be attributed to the lack of complete settlement due to the high normal stress and inadequate consolidation time for clay. For the applied normal stress of $350 \mathrm{kPa}$ and interface \#0, no significant dilative behaviour was observed during the shearing process, which may be due to the higher applied normal stress and the low roughness.

2.5.2. Effect of the Initial Normal Stress. Figure 6 shows the test results for interface \#0 with different initial normal stresses of shearing under a normal stress of $100 \mathrm{kPa}$. The shear-stress-displacement and vertical-displacementshear-displacement relationships for the interface between clay and concrete plates \#1 and \#2 are presented in Figures 7 and 8 , respectively. From these plots, it is observed that higher initial normal stresses produce higher shear stresses during shearing, apart form the curve of initial normal stress $300 \mathrm{kPa}$ on plate \#1 and plate \#2. This result may be attributed to shear test uncertainties and experimental variations from sample to sample. The shear stiffness was not found to be significantly influenced by the initial normal stress. Figures 6 , 7 , and 8 exhibit the influence of the initial normal stress on the dilation phenomenon of the interface under the normal stress of $100 \mathrm{kPa}$. For interfaces not experiencing the progress of normal unloading, the soil near the interface is contracted before dilating. Note that the dilation from the start of shear for the interfaces of initial normal stress over $100 \mathrm{kPa}$ experiences normal unloading. Moreover, a greater vertical displacement occurred for a higher initial normal stress. Therefore, the results validate the effect of the normal stress history on the deformational behaviour of the interface.
2.5.3. Effect of Interface Roughness. For an interface not experiencing normal unloading, the conclusions that a rougher interface exhibits higher shear strength and higher shear stiffness have been stated by many researchers. The roughness of the interface was found to have an effect on the shear zone thickness and shear failure model and to even control the movement style of the soil particles along the interface $[7,15]$. However, the strength of the interface does not increase indefinitely with the roughness, according to Zeghal et al. [15]. They identified a bilinear relationship between the surface roughness and the interface friction. Below a certain "critical" roughness, the interface shear resistance increased with roughness, up to the point where the interface shear efficiency parameter reached 1.0. Dove and Jarret took the ruled topography interface to validate the existence of a "critical" roughness; asperity angles greater than approximately 50 degrees caused shear within the soil above the interface, resulting in the lack of the observation of increasing strength [13]. In this experiment, the original planed heights of asperity were $0,1,2$, and $3 \mathrm{~cm}$. The stress from \#3 interface was found to be below the corresponding value of \#2 and, sometimes, even below that of the \#1 interface. This phenomenon can be explained by the conclusion given by Dove and Jarret [13]. Through a comparison of the shear stresses of \#0, \#1, and \#2 interfaces in Figure 9, the same conclusion can be made: higher asperity offers a higher shear stress. The shear-contractive phase was found at the beginning of the shear for the interfaces not experiencing normal unloading, with a longer shear-contractive phase for a smoother interface. Interface \#0 traversed from the shear-contractive phase to the shear-dilative phase at a shear displacement of $11 \mathrm{~mm}$, while the traversal occurred at a shear displacement of $8 \mathrm{~mm}$ for interface $\# 1$ and of $2 \mathrm{~mm}$ for interface \#2. The higher contractive value was found to correspond to the smoother interface. The higher asperity results in a higher asperity angle if the width of the asperity remains constant, and the soil near the interface was found to receive more of the vertical component of the force for a higher asperity angle. Therefore, more shear-dilative displacement occurs for a rougher interface.

For the interfaces experiencing normal unloading, the effect from the roughness can be analysed through the maximum shear stress during shear. Similar to the interface 

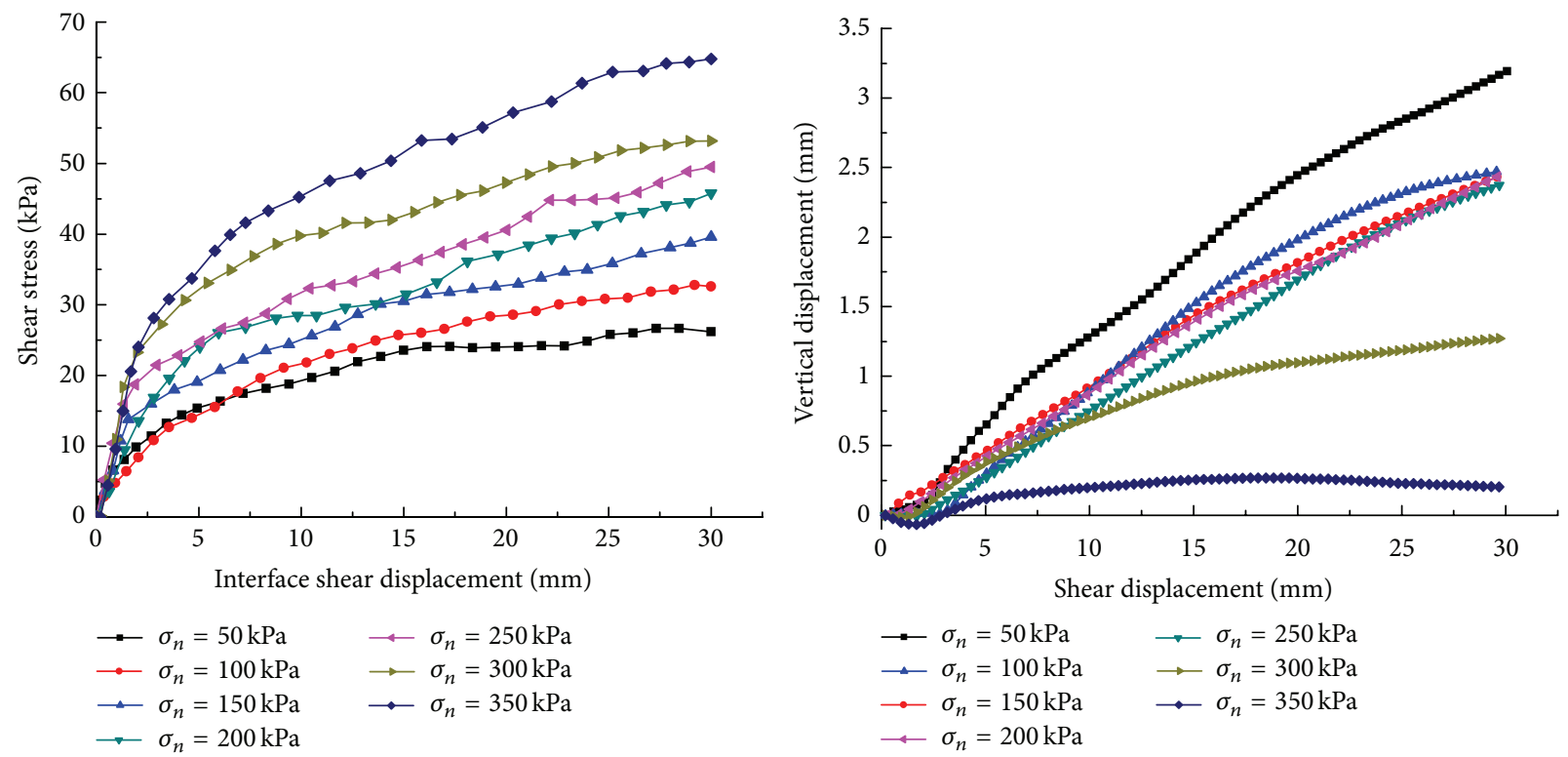

FIGURE 3: Test results for the interface between clay and \#0 plate (initial normal stress of $400 \mathrm{kPa}$ ).
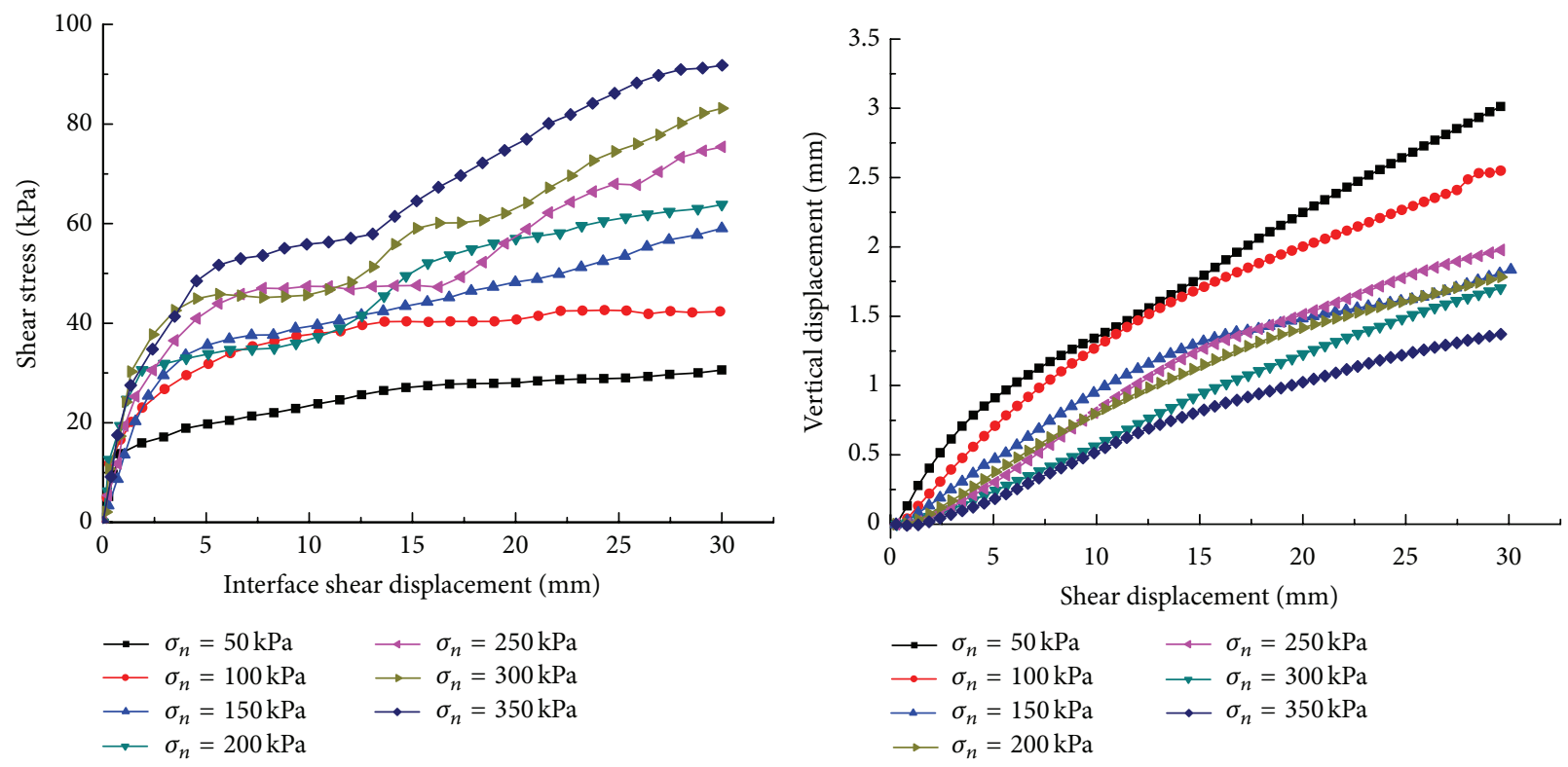

FIGURE 4: Test results for the interface between clay and \#1 plate (initial normal stress of $400 \mathrm{kPa}$ ).

not experiencing normal unloading, the rougher interface exhibits a higher maximum shear stress, as depicted in Figure 10; \#2 interface exhibited the highest maximum shear stress under the same stress history, the second highest was for \#1 interface, and \#0 interface had the lowest value. As the initial normal stress increased, the effect from the roughness on the maximum shear stress became increasingly obvious. To analyse the effect of roughness on the dilative phenomenon, we take the data from the interfaces experiencing normal stress unloading in the range from $200 \mathrm{kPa}$ to $100 \mathrm{kPa}$ as an example (the other interfaces had the same shear-dilative trend). Figure 11 shows the higher dilative displacement observed for a rougher interface; the maximum vertical displacement was $2.87 \mathrm{~mm}$ for \#2 interface, $2.49 \mathrm{~mm}$ for \#1 interface, and only $1.81 \mathrm{~mm}$ for \#0 interface.

\section{Model Description}

Due to the analogy between the behaviours of soil and the interface between soils and structures, the proposed model frame is based on the model of internal shear in soils [16]. According to Liu et al. [16], the incremental stress tensor can be expressed as

$$
\{d \sigma\}=\left\{\begin{array}{c}
d \sigma_{n} \\
d \tau
\end{array}\right\}=[K]\left\{\begin{array}{l}
d u_{n} \\
d u_{s}
\end{array}\right\},
$$



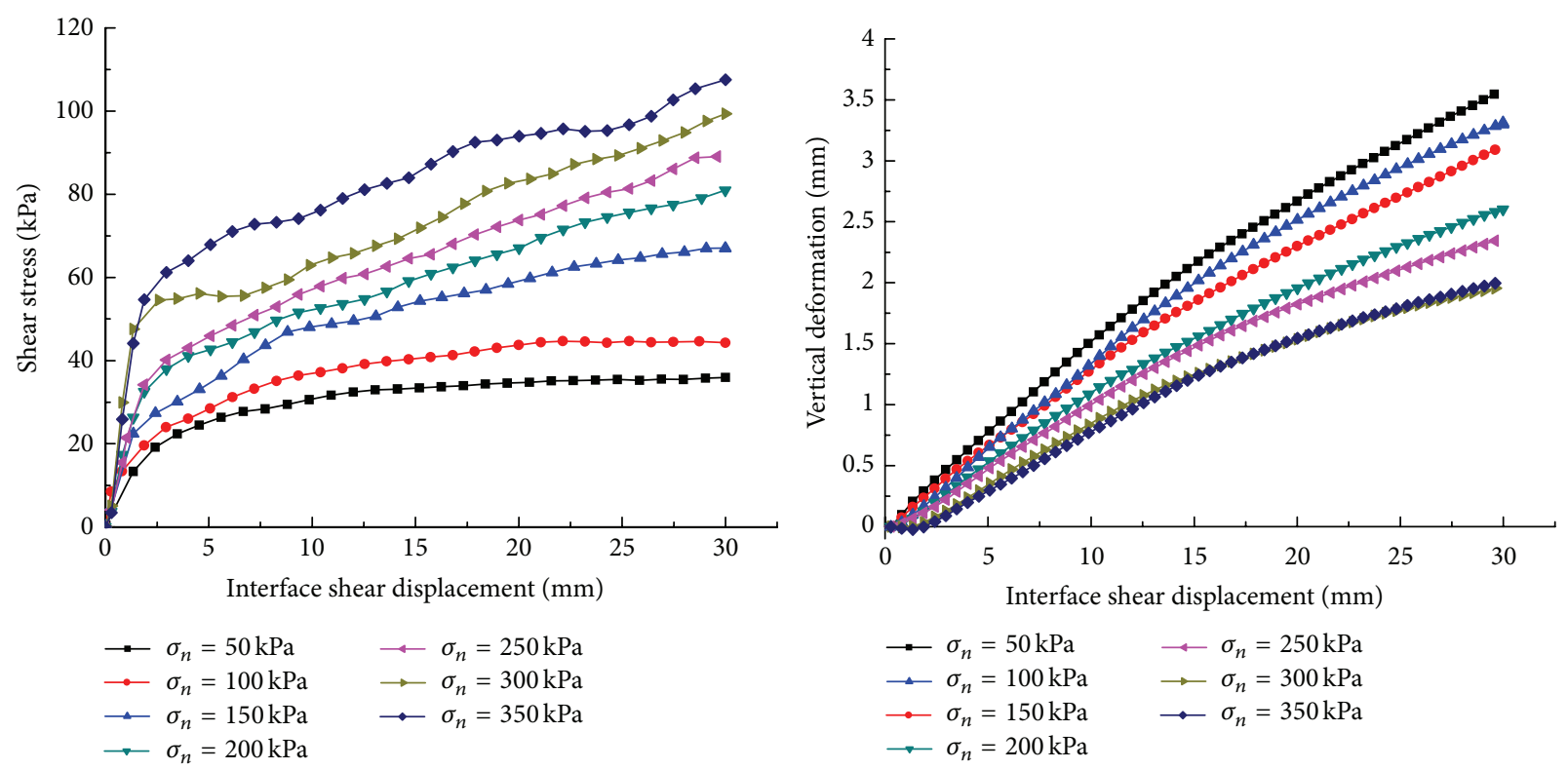

FIGURE 5: Test results for the interface between clay and \#2 plate (initial normal stress of $400 \mathrm{kPa}$ ).
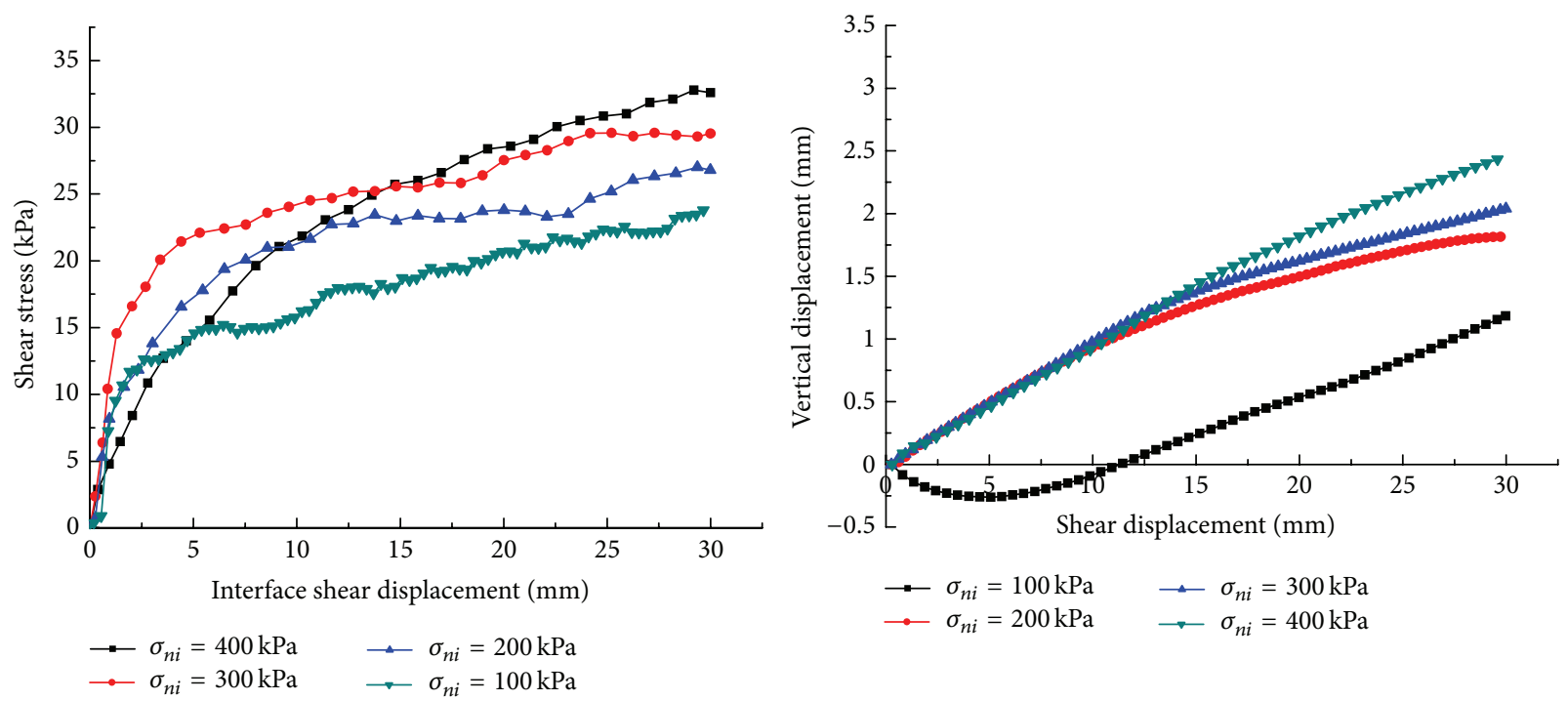

FIgURE 6: Test results for the interface between plate \#0 and clay (applied normal stress of $100 \mathrm{kPa}$ ).

in which $d \sigma_{n}$ and $d \tau$ are the incremental normal and shear stresses, respectively, and $d u_{n}$ and $d u_{s}$ are the incremental normal and tangential displacements, respectively. All the parameters can be obtained directly from the test. While the interface is not purely smooth, the researchers $[7,12,17,18]$ found that a shear band exists near the interface during shear. The thickness $t$ was observed to equal five times the diameters of the sand at the interface between the sand and the structure. For the interface with clay, determining the value of $t$ has not been studied. In the direct shear test, the thickness of the shear band cannot be determined because the shear is limited along the plane. As a result, the value of $t$ is set to a constant value in the sections below. An internal strain was assumed, even in the shear band. Consider

$$
\begin{aligned}
& d \varepsilon_{n}=\frac{d u_{n}}{t}, \\
& d \varepsilon_{s}=\frac{d u_{s}}{t},
\end{aligned}
$$

where $d \varepsilon_{n}$ and $d \varepsilon_{s}$ are the incremental normal and shear strain, respectively. Thus, the matrix can be expressed as

$$
[K]=t\left[D^{e p}\right] .
$$



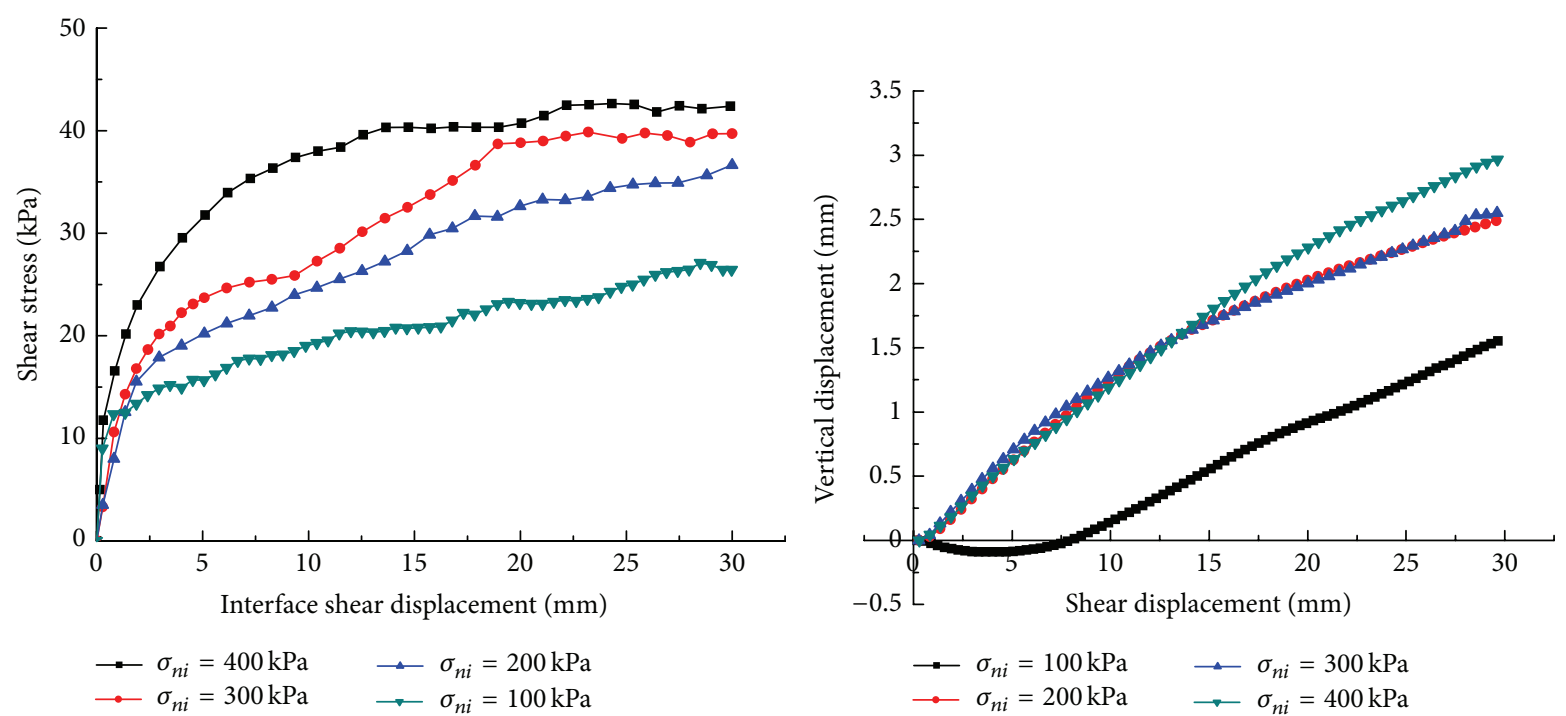

Figure 7: Test results for the interface between plate \#1 and clay (applied normal stress of $100 \mathrm{kPa}$ ).
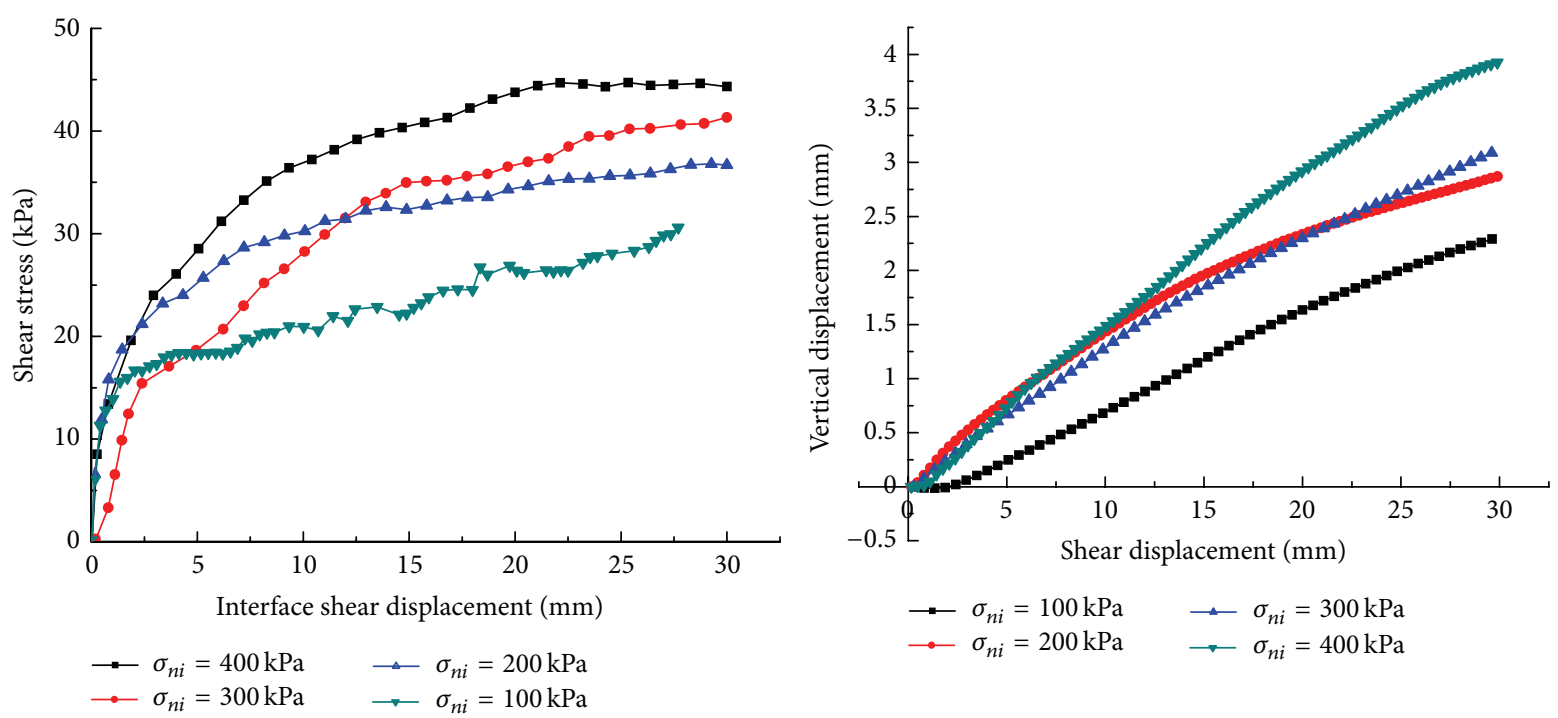

FIGURE 8: Test results for the interface between plate \#2 and clay (applied normal stress of $100 \mathrm{kPa}$ ).

Here, $\left[D^{e p}\right]$ is the elastoplastic constitutive matrix; Morched Zeghal et al. and Zhou Guo-qing et al. proposed the expression of $\left[D^{e p}\right]$. To simplify the model, the associated flow rule is applied in the proposed model as follows:

$$
\left[D^{e p}\right]=\left[D^{e}\right]-\frac{\left[D^{e}\right]\{n\}^{T}\{n\}\left[D^{e}\right]}{H+M+\{n\}\left[D^{e}\right]\{n\}^{T}},
$$

where $H$ is the hardening parameter, while $M$ describes the influence of the change in the interfacial frictional coefficient with the stress state. In this proposed model, the interfacial frictional coefficient is assumed to be constant during shear $(M=0)$ to perform the research on the effect of normal stress history. The energy accumulated at the interface, $W_{p}$, is taken as the hardening parameter:

$$
\begin{aligned}
H=W_{p}= & \int_{\text {loading }} d \sigma d \mu_{n}+\int_{\text {loading }} \sigma_{n i} d \mu_{n}-\int_{\text {unloading }} d \sigma d \mu_{n} \\
& -\int_{\text {sheering }} d \sigma d \mu_{n}-\int_{\text {sheering }} d \tau d \mu_{s} .
\end{aligned}
$$

During the loading, the initial energies accumulated at the interface are $\int_{\text {loading }} d \sigma d \mu_{n}$ and $\int_{\text {loading }} \sigma_{n i} d \mu_{n}$, and the energy released during the normal unloading is $\int_{\text {unloading }} d \sigma d \mu_{n}$. During shearing, the energy consumed to 

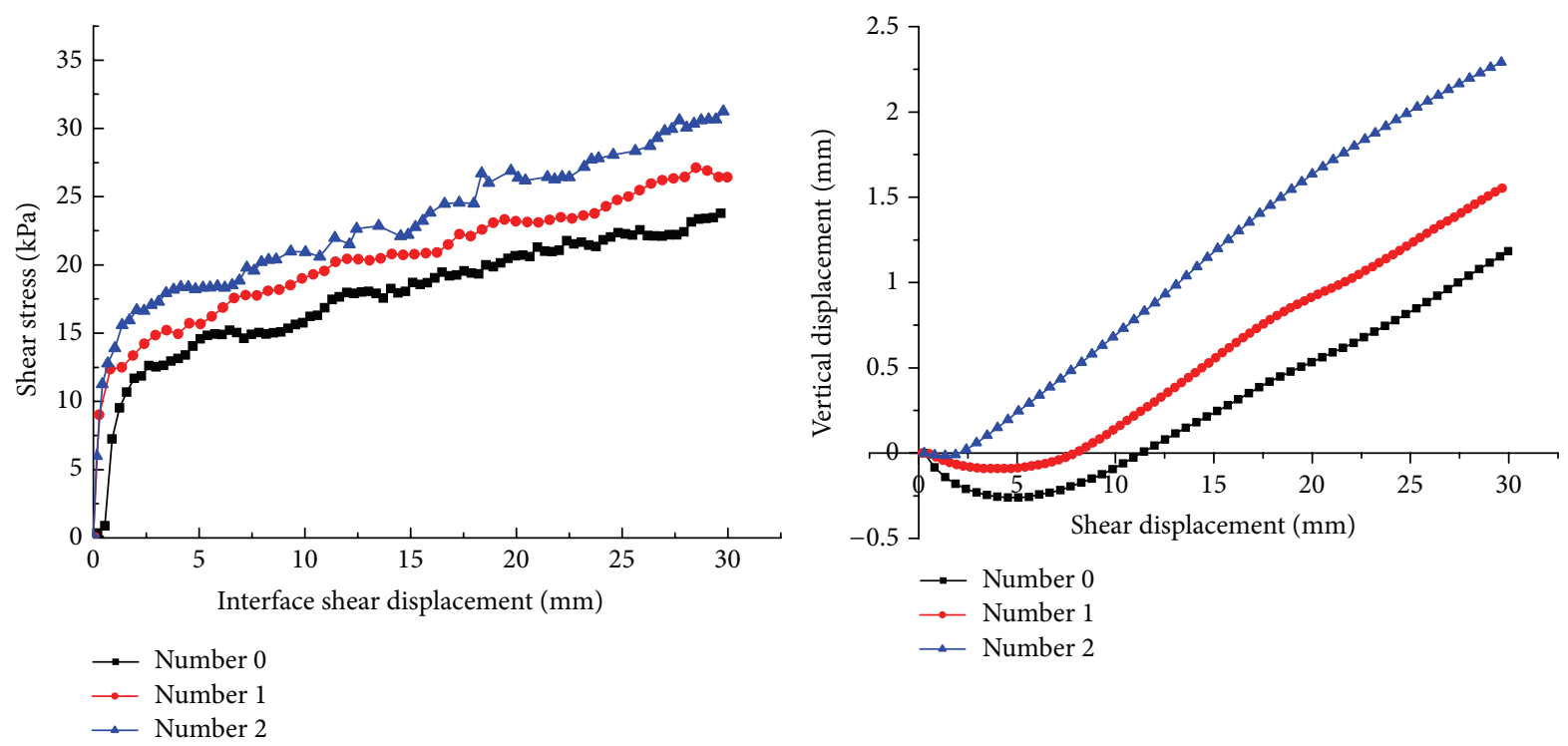

FIGURE 9: Test results for an interface not experiencing normal unloading (normal stress of $100 \mathrm{kPa}$ ).

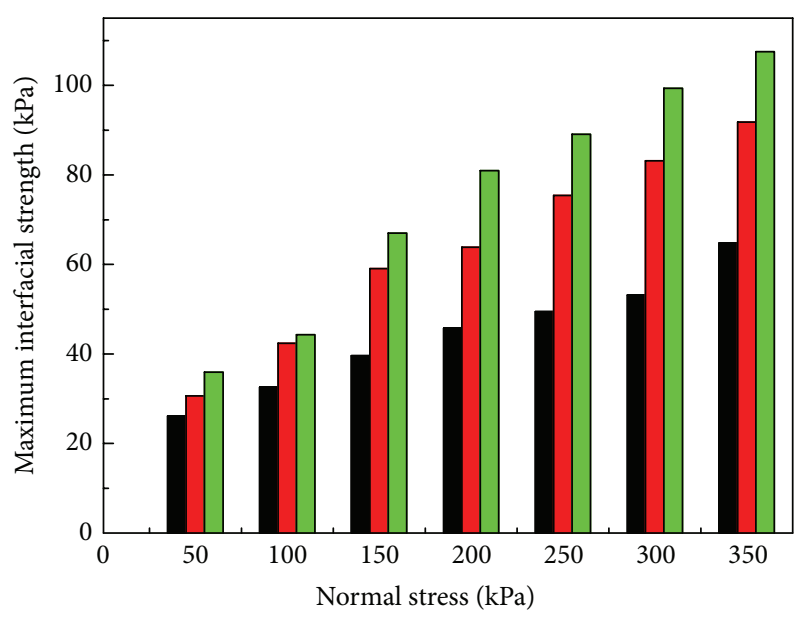

Number 0

Number 1

Number 2

FIGURE 10: The maximum shear stress versus the normal stress for interfaces of different roughness.

do work is $\int_{\text {sheering }} d \tau d \mu_{s}$. Meanwhile, energy continues to be accumulated in the amount of $\int_{\text {sheering }} d \sigma d \mu_{n}$ for the shearcontractive interface but is consumed for the shear-dilatant interface.

$\left[D^{e}\right]$ is the elastic constitutive matrix, in which nonlinear elasticity is used. For simplicity, the elastic moduli in the normal and tangential directions are assumed to be uncoupled:

$$
\left[D^{e}\right]=\left[\begin{array}{cc}
D_{n} & 0 \\
0 & D_{s}
\end{array}\right]
$$

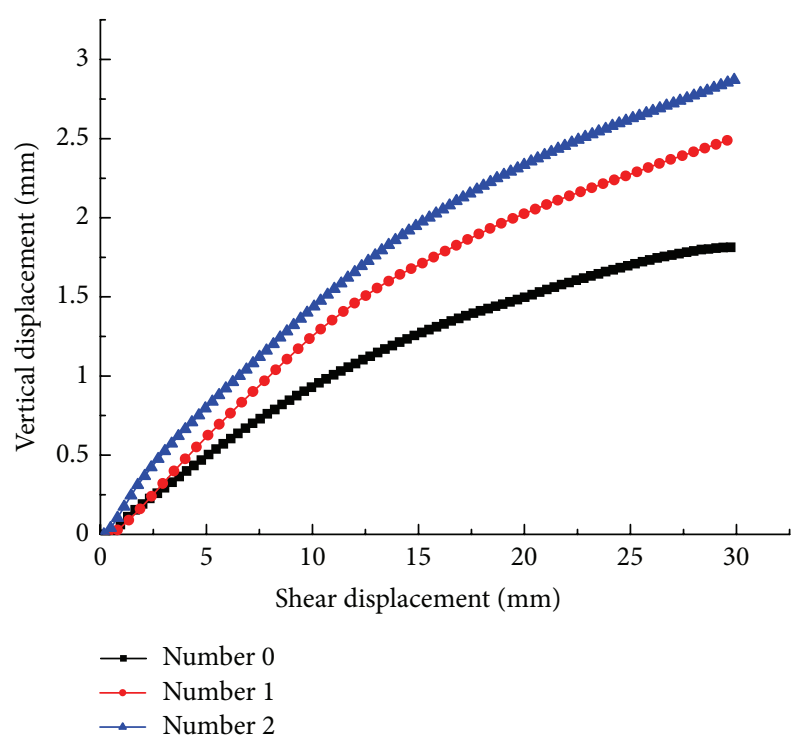

FIgURE 11: The vertical dilative displacement for interfaces of different roughness.

where $D_{n}$ and $D_{s}$ are the normal and tangential moduli, respectively, which are both influenced by the stress history and stress state, according to Desai C. S.

Liu et al. [16] identified the loading direction vector $\{n\}$ as

$$
\{n\}=\left(\frac{d_{f}}{\sqrt{1+d_{f}^{2}}} \frac{1}{\sqrt{1+d_{f}^{2}}}\right) .
$$

The parameter $d_{f}$ is related to the stress state and the initial state of the interface; however, it cannot capture the loading direction of the sawtooth interface in our large test. Morched Zeghal and coworkers modelled the interface as 


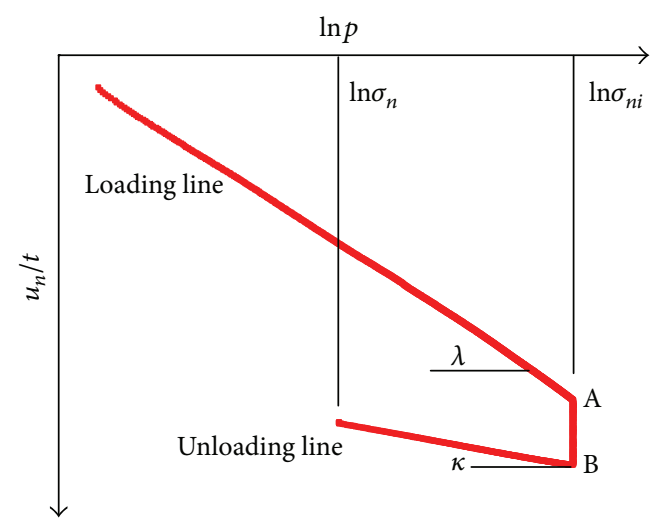

FIGURE 12: $u_{n}-\ln p$ plots of the loading and unloading process in the tests.

a ruled sawtooth. According to their approach, the loading direction of the sawtooth should be

$$
\begin{aligned}
& \{n\}=\left\{\begin{array}{ll}
\frac{\partial F}{\partial \sigma_{n}} & \frac{\partial F}{\partial \tau}
\end{array}\right\} \\
& =\left\{\sin \alpha_{k}+u \cos \alpha_{k} \cos \alpha_{k}-u \sin \alpha_{k}\right\} .
\end{aligned}
$$

Here, $u$ is the frictional coefficient of the interface when the sawtooth height is equal to zero. $\alpha_{k}$ is the topography parameter.

\section{Identification of the Model Parameters}

4.1. Elastic Moduli: $D_{n}$ and $D_{s}$. The normal elastic moduli $D_{n}$ can be determined from the loading-unloading curve of $u_{n}-\ln p$, as shown in Figure 12; the displacement of the $\mathrm{AB}$ section is deduced from the primary consolidation of the clay under the initial normal stress, and the resilience occurring as the initial normal stress $\sigma_{n i}$ is unloaded to the normal stress $\sigma_{n}$. The slope coefficient of the resilience line was signified by $\kappa$. Thus, the normal moduli can be determined as.

$$
D_{n}=\frac{\sigma_{n}}{\kappa} .
$$

The hyperbolic model was validated by many test results, which measured the shear moduli changes with shear displacement. Consider

$$
D_{s}=\frac{a}{\left(a+b \varepsilon_{s}\right)^{2}}
$$

where $a=1 / D_{s i}, b=\sigma_{n} / \tau_{\text {ult }}$, and $\tau_{\text {ult }}$ is the ultimate shear strength of the critical state in the test; thus, $b=1 / \eta_{c}$. From Figures $3-8$, the peak shear strength is not yet reached, even when the shear displacement is accumulated to $30 \mathrm{~mm}$, which is the limit displacement of this test because, under operational conditions, the accumulation of $30 \mathrm{~mm}$ of lateral displacement was observed to possibly result in excessive leakage of soil. Thus, the destructional ratio $R_{f}$ is introduced:

$$
\begin{gathered}
R_{f}=\frac{\tau_{f}}{\tau_{\text {ult }}}, \\
D_{s}=D_{s i}\left(1-R_{f} \frac{\tau}{\tau_{f}}\right)^{2},
\end{gathered}
$$

where $\tau_{f}$ is the shear stress as the shear displacement reaches $30 \mathrm{~mm}$ and $\tau_{\text {ult }}$ is determined through curve fitting. $D_{s i}$ are the initial tangent shear moduli, which are described by Anubhav P.K. and coworkers; where an increase in the normal stress will result in steeper shear-relative displacement curves and a higher strength, and the values of $D_{s i}$ and $\tau_{\text {ult }}$ therefore will increase with the increase in normal stress. This stress dependence is taken into account by using empirical equations to represent the variation of $D_{s i}$ with normal stress:

$$
D_{s i}=K P_{a}\left(\frac{\sigma_{n}}{P_{a}}\right)^{n},
$$

where $K$ is the modulus number and $n$ is the modulus exponent (both are dimensionless numbers), and $P_{a}$ is the atmospheric pressure. However, the modulus number and the modulus exponent must be determined through curve fitting, which limits the application of the proposed model. At the beginning of shear, the deformation can be assumed to be elastic, so the initial shear modulus can be expressed as follows. According to the relationship between the normal elastic modulus and the shear elastic modulus and by analogy between the behaviours of soil and the interface between soil and structures,

$$
D_{s i}=\frac{D_{n}}{2(1+\nu)}=\frac{\sigma_{n}}{2 \kappa(1+\nu)},
$$

where $v$ is Poisson's ratio of the soil. However, the above equation cannot incorporate the influence of normal stress history on the initial shear modulus. G.T. Houlsby and C.P. Wroth performed a research on the stress history of soil; the initial shear modulus that can account for the effect of stress history was expressed as

$$
G_{o c}=G_{n c}\left(\frac{\sigma_{n i}}{\sigma_{n}}\right)^{0.7}
$$

where $G_{o c}$ is the initial shear modulus during overconsolidation of soil and $G_{n c}$ is the initial shear modulus during normal consolidation of soil. Note that the exponent has the value of 0.7 only for the situation of an overconsolidation ratio below 10. Therefore, the initial shear modulus of the proposed model can be given by

$$
D_{s i}=\frac{\sigma_{n}}{2 \kappa(1+\nu)}\left(\frac{\sigma_{n i}}{\sigma_{n}}\right)^{0.7} .
$$

Finally, the shear modulus that accounts for the effect of normal stress history is

$$
D_{s}=\frac{\sigma_{n}}{2 \kappa(1+\nu)}\left(\frac{\sigma_{n i}}{\sigma_{n}}\right)^{0.7}\left(1-R_{f} \frac{\tau}{\tau_{f}}\right)^{2} .
$$




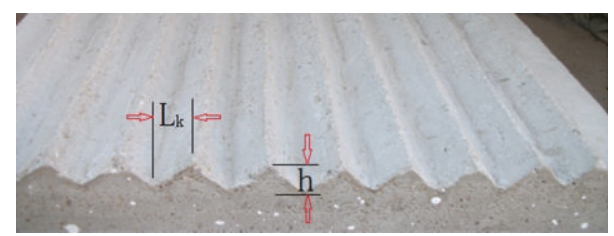

FIGURE 13: The topography parameters of the concrete plate used in the test.

4.2. The Topography Parameter $\alpha_{k}$. The ruled topography concrete plates were used in the large shear test. For such a sawtooth interface, Morched Zeghal defined $\alpha_{k}$ as

$$
\alpha_{k}=\frac{\pi h}{2 L_{k}} \sin \frac{\pi}{2}\left(1+\frac{u_{s}}{L_{k}}\right)
$$

in which $h$ and $L_{k}$ are the height and width, respectively, of the sawtooth, as illustrated in Figure 13.

4.3. Hardening Parameter $H$. $\int_{\text {loading }} d \sigma d \mu_{n}$ and $\int_{\text {unloading }} d \sigma$ $d \mu_{n}$ could by computed from the normal loading-unloading curve, as shown in Figure 12. Consider

$$
\begin{aligned}
& \int_{\text {loading }} d \sigma d \mu_{n}=\int_{1}^{\sigma_{n i}}\left(u_{n 0}+\lambda \ln p\right) d p, \\
& \int_{\text {unloading }} d \sigma d \mu_{n}=\int_{\sigma_{\mathrm{ni}}}^{\sigma_{n}}\left(u_{n i}-\kappa \ln p\right) d p,
\end{aligned}
$$

where $u_{n 0}$ is the normal displacement at the normal stress of $1 \mathrm{kPa}$ and $u_{n i}$ is the normal displacement at the beginning of unloading (the B point in Figure 12), while $\lambda$ and $\kappa$ are the slope coefficients of the loading and unloading lines, respectively.

$\int_{\text {loading }} \sigma_{n i} d \mu_{n}$ is the power accumulated during the progress of consolidation under the initial normal stress, and the stress remains constant in this period. Thus, the power is

$$
\int_{\text {loading }} \sigma_{n i} d \mu_{n}=\sigma_{n i}\left(u_{n B}-u_{n A}\right) .
$$

As illustrated in Figure 11, $u_{n A}$ and $u_{n B}$ are the displacement at the end of the loading period and the beginning of the unloading, respectively.

Both $\int_{\text {sheering }} d \tau d \mu_{s}$ and $\int_{\text {sheering }} d \sigma d \mu_{n}$ should be determined through iteration. First, assuming the relationship $\tau-\mu_{s}$ follows a hyperbolic model, the initial value of $\tau$ can be computed by substituting the shear displacement $(0-30 \mathrm{~mm})$ into the hyperbolic model. Next, the initial value of $\tau$ can be substituted into (1) to determine the new displacement value, which enables the initial hardening parameter to be computed. The new value of $\tau$ is then recomputed based on the initial hardening parameter, and then, the new shear displacement and new shear stress are calculated. The final shear stress and displacement are computed when the error tolerance is satisfied.

\section{Model Validation}

The predicted results of the model are shown in Figures 14(a), 14(b), and 14(c) together with the experimental results for the \#0, \#1, and \#2 interfaces first under the initial normal stress of $400 \mathrm{kPa}$ then being unloaded to the normal stress of $50-350 \mathrm{kPa}$. The model is able to reproduce the behaviour of the clay-concrete interface with different normal stresses, different initial normal stresses, and roughness. Note that the model simulated the shear-stress-displacement relationship to a satisfactory degree, which is very important for pile-soil interface and retaining wall problems. From Figure 14, the shear stress is found to increase quickly with displacement, and as shear progressed, the dissipative power $\int_{\text {sheering }} d \tau d \mu_{s}$ increased; meanwhile, the power accumulated at the interface $\mathrm{H}$ was consumed slowly. During the last half of the shear progress, the shear stress increases gradually with displacement and finally approaches a constant value.

Figures 15(a), 15(b), and 15(c) show the shear stress versus horizontal displacement along the interface between concrete plates $\# 0, \# 1$, and $\# 2$, respectively, and clay with different initial normal stresses and shearing under a normal stress of $100 \mathrm{kPa}$. The higher initial normal stress results in higher power $\int_{\text {loading }} d \sigma d \mu_{n}$ and $\int_{\text {loading }} \sigma_{n i} d \mu_{n}$ accumulated at the interface and results in higher shear stiffness. From the microcosmic viewpoint, the higher initial normal stress causes the soil near the interface to reach a higher compressive strength. Another reasonable explanation is that the clay is more closely embedded into the sawtooth topography for the higher initial normal stress. The cohesive section of the shear strength of the interface is formed by the absorption of water molecules in the clay and the surface of the concrete plate; under the pressure of the initial normal stress, the water molecules in the clay will penetrate into the concrete plate and keep inside.

\section{Conclusions}

First, using sawtooth-surfaced concrete plates to quantify the roughness of the interface, a series of shear tests were conducted to analyse the effects of roughness and unloading on the shear behaviour of the interface between clay and concrete. Based on the results of direct shear tests on the clay-concrete interface, the following conclusions can be proposed.

Through the process of loading to an initial normal stress, unloading to normal stress and shearing under this normal stress, the shear behaviour of the interface between clay and concrete was found to be influenced by the initial normal stress and the roughness of the interface. A higher initial normal stress results in a higher shear stress during the shearing. Under the same initial normal stress, a lower value of shear stiffness was observed for a higher unloading ratio (a lower normal stress during shearing). The effect of roughness on the shear behaviour is revealed through the shear stressdisplacement relation and the normal dilative phenomenon. Regardless of whether normal unlading occurred or not the 

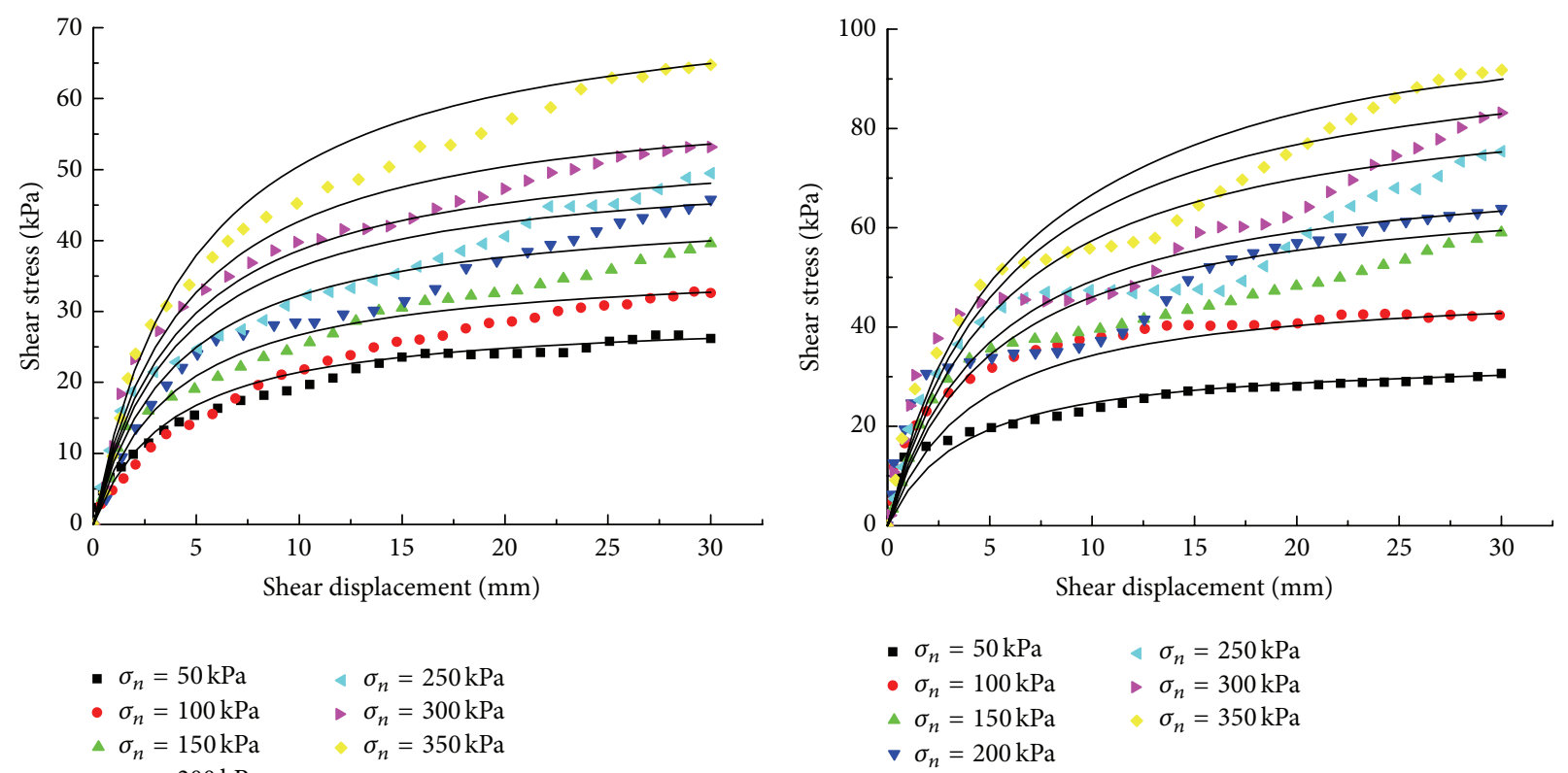

$\begin{array}{rll}\text { - } \sigma_{n}=50 \mathrm{kPa} & \triangleleft \sigma_{n}=250 \mathrm{kPa} \\ \text { - } \sigma_{n}=100 \mathrm{kPa} & \rightarrow \sigma_{n}=300 \mathrm{kPa} \\ \text { - } \sigma_{n}=150 \mathrm{kPa} & \diamond \sigma_{n}=350 \mathrm{kPa} \\ \text { - } \sigma_{n}=200 \mathrm{kPa} & \end{array}$

(a)

(b)

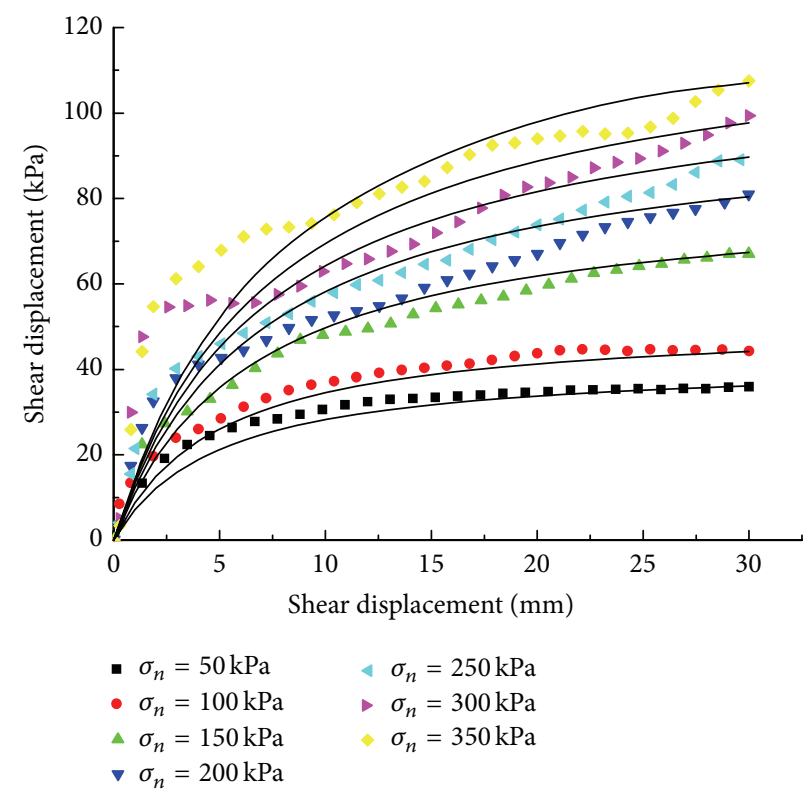

(c)

FIGURE 14: Shear-stress-displacement curves of the interface between clay and concrete $\left(\sigma_{n i}=400 \mathrm{kPa}\right)$.

rougher interface offers a higher shear stress and vertical displacement.

The shear-dilative behaviour is significantly influenced by the stress history. The shear-contractive phase occurs at the beginning of shear for the interfaces that do not experience normal unloading, while no such contractive displacement was found for interfaces experiencing unloading of the initial normal stress $\sigma_{n i}$ to the applied normal stress $\sigma_{n}$ before shear.
Finally, a model that can account for the effect of normal stress history was proposed. The parameters of the model all have definite physical meanings. The calibration and validation of the model were performed by simulating laboratory test results conducted in a newly developed large direct shear apparatus. The results demonstrated that the model is capable of predicting the behaviour of clay-concrete interfaces and of capturing the effects of different normal stress history and roughness. 


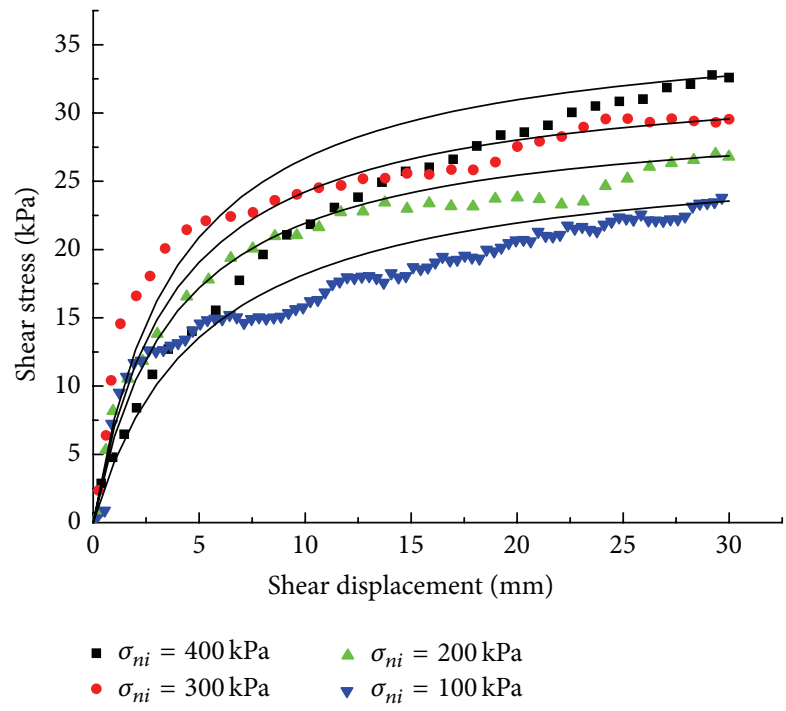

(a)

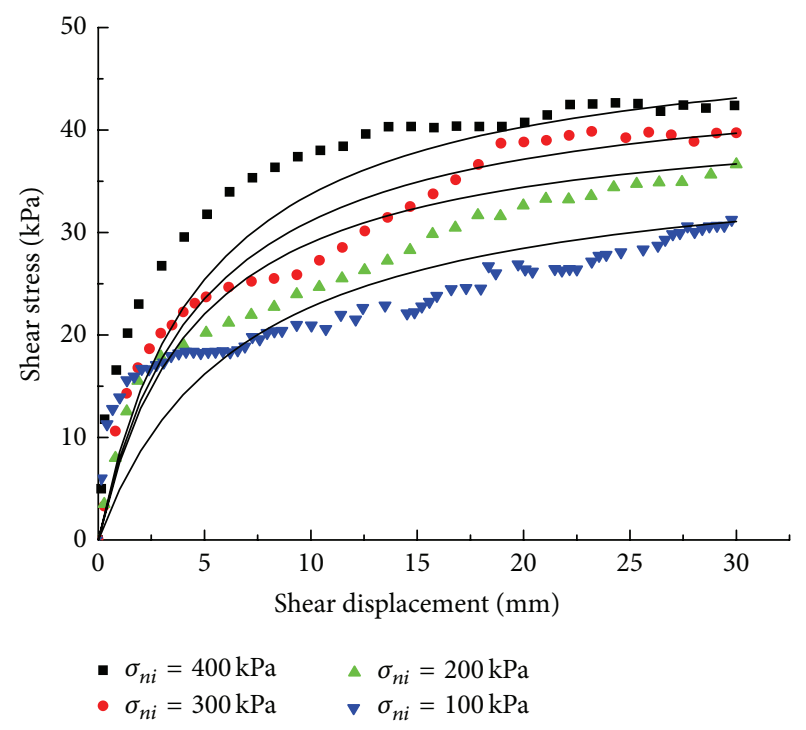

(b)

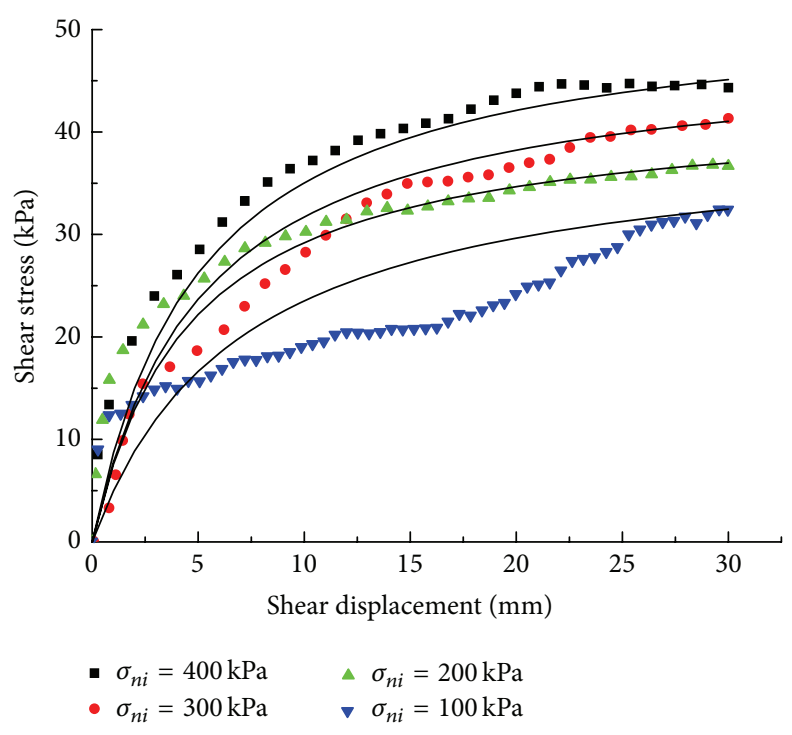

(c)

FIGURE 15: Shear-stress-displacement curves of the interface between clay and concrete $\left(\sigma_{n}=100 \mathrm{kPa}\right)$.

\section{Acknowledgments}

The present study was supported by the National Natural Science Foundation Project (41202193), the Shanghai Pujiang Program (11PJ1410100), and the Kwang-Hua Fund for the College of Civil Engineering, Tongji University.

\section{References}

[1] G. W. Clough and J. M. Dunan, "Finite element analyses of retaining wall behavior," Journal of the Soil Mechanics and Foundations Division, vol. 97, no. 12, pp. 1657-1673, 1971.

[2] J. E. Ǵomez, G. M. Filz, and R. M. Ebeling, "Extended hyperbolic model for sand-to-concrete interfaces," Journal of
Geotechnical and Geoenvironmental Engineering, vol. 129, no. 11, pp. 993-1000, 2003.

[3] C. S. Desai, E. C. Drumm, and M. M. Zaman, "Cyclic testing and modeling of interfaces," Journal of Geotechnical Engineering, vol. 111, no. 6, pp. 793-815, 1985.

[4] M. Boulon and C. Plytas, "Soil-structure directionally dependent interface constitutive equation-application to the prediction of shaft friction along piles," in Proceedings of the 2nd International Symposium on Numerical Models in Geomechanics, pp. 43-54, Ghent, Belgium.

[5] M. Boulon and R. Nova, "Modelling of soil-structure interface behaviour a comparison between elastoplastic and rate type laws," Computers and Geotechnics, vol. 9, no. 1-2, pp. 21-46, 1990. 
[6] V. N. Ghionna and G. Mortara, "An elastoplastic model for sand-structure interface behaviour," Geotechnique, vol. 52, no. 1, pp. 41-50, 2002.

[7] L. Hu and J. Pu, "Testing and modeling of soil-structure interface," Journal of Geotechnical and Geoenvironmental Engineering, vol. 130, no. 8, pp. 851-860, 2004.

[8] G. A. Zhang and J. M. Zhang, "Large-scale apparatus for monotonic and cyclic soil-structure interface test," Geotechnical Testing Journal, vol. 29, no. 5, pp. 401-408, 2006.

[9] G. A. Zhang and J. M. Zhang, "Monotonic and cyclic tests of interface between structure and gravelly soil," Soils and Foundations, vol. 46, no. 4, pp. 505-518, 2006.

[10] G. Zhang, D. Liang, and J. M. Zhang, "Image analysis measurement of soil particle movement during a soil-structure interface test," Computers and Geotechnics, vol. 33, no. 4-5, pp. 248-259, 2006.

[11] E. Evgin and K. Fakharian, "Cyclic rotational simple-shear behaviour of sand-steel interfaces," Soils and Foundations, vol. 38, no. 2, pp. 191-199, 1998.

[12] J. E. Gómez, G. M. Filz, R. M. Ebeling, and J. E. Dove, "Sandto-concrete interface response to complex load paths in a large displacement shear box," Geotechnical Testing Journal, vol. 31, no. 4, pp. 358-369, 2008.

[13] J. E. Dove and J. B. Jarrett, "Behavior of dilative sand interfaces in a geotribology framework," Journal of Geotechnical and Geoenvironmental Engineering, vol. 128, no. 1, pp. 25-37, 2002.

[14] O. Nasir and M. Fall, "Shear behaviour of cemented pastefillrock interfaces," Engineering Geology, vol. 101, no. 3-4, pp. 146153, 2008.

[15] M. Zeghal, T. B. Edil, and M. E. Plesha, "Discrete element method for sand-structure interaction," in Proceedings of the $3 \mathrm{rd}$ International Conference on Discrete Element Methods, pp. 317322, Santa Fe, NM, USA, September 2002.

[16] H. Liu, E. Song, and H. I. Ling, "Constitutive modeling of soilstructure interface through the concept of critical state soil mechanics," Mechanics Research Communications, vol. 33, no. 4, pp. 515-531, 2006.

[17] C. S. Desai and D. B. Rigby, "Cyclic interface and joint shear device including pore pressure effects," Journal of Geotechnical and Geoenvironmental Engineering, vol. 123, no. 6, pp. 568-579, 1997.

[18] M. T. Luan and Y. J. Wu, "Nonlinear elasto-perfectly plastic model of interface element for soil-structure interaction and its applications," Rock and Soil Mechanics, vol. 25, no. 4, pp. 507513, 2004 (Chinese). 


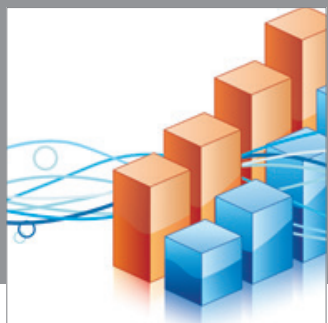

Advances in

Operations Research

mansans

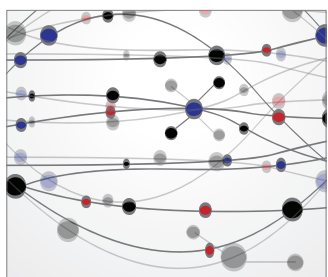

The Scientific World Journal
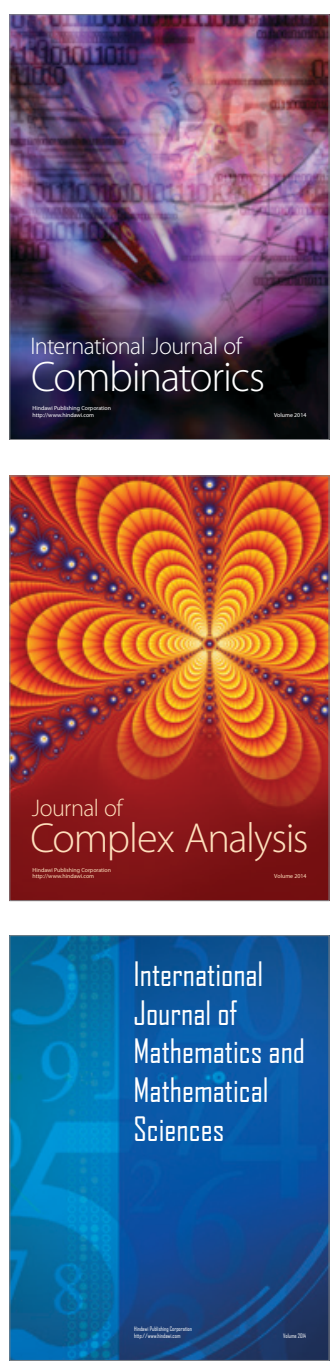
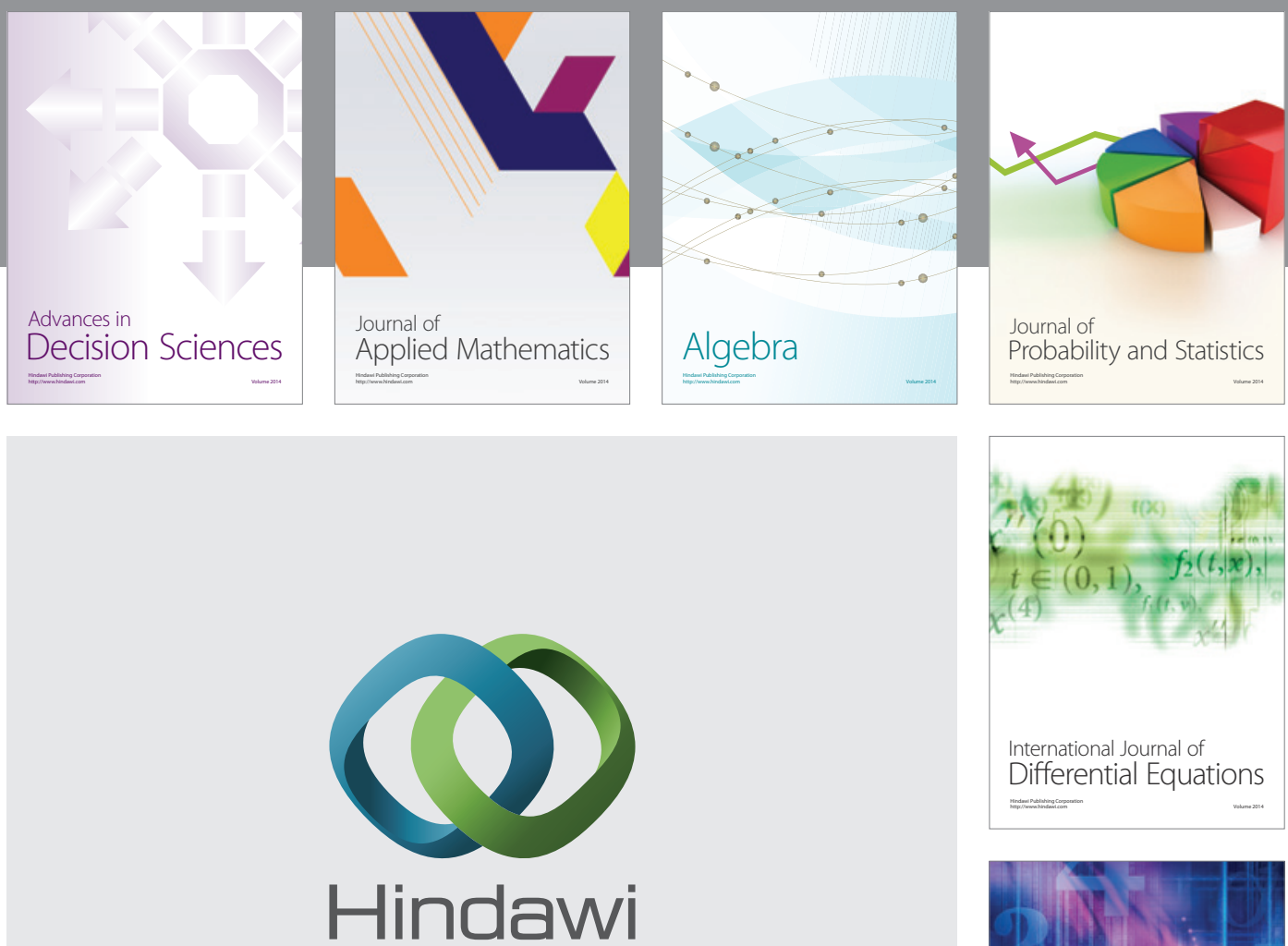

Submit your manuscripts at http://www.hindawi.com
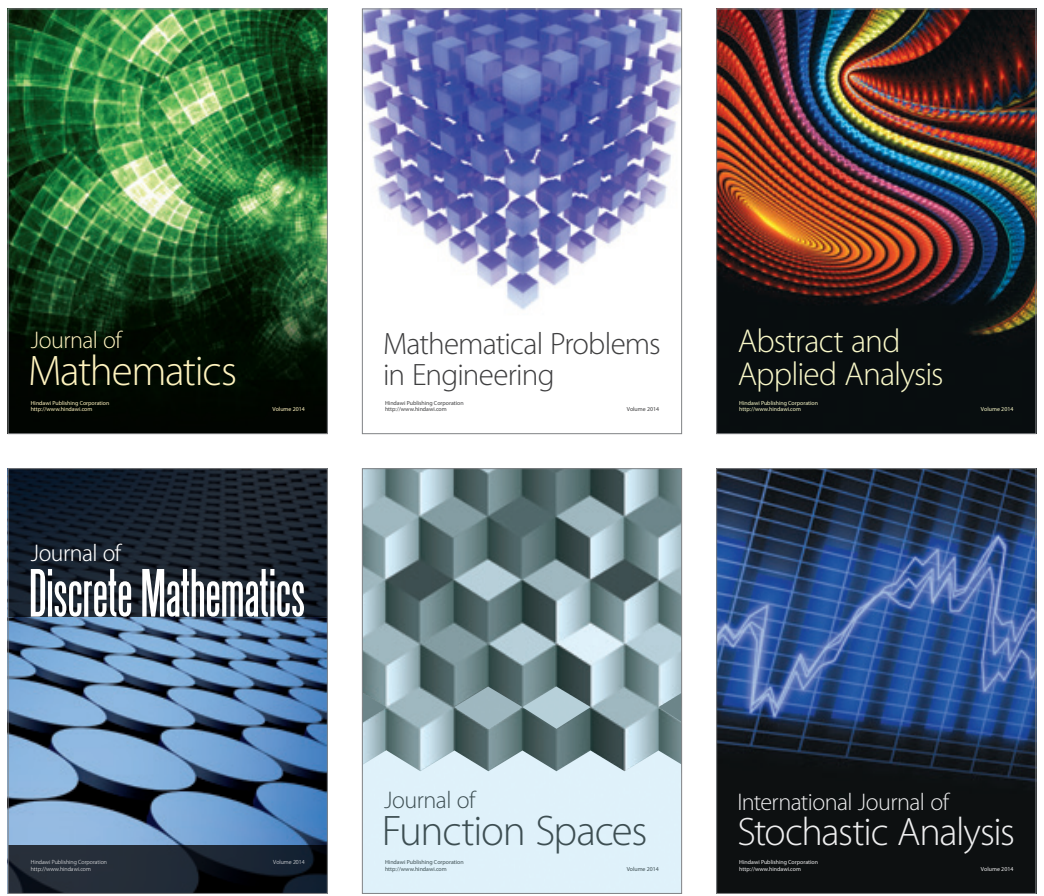

Journal of

Function Spaces

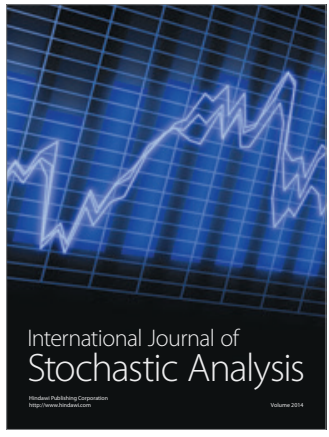

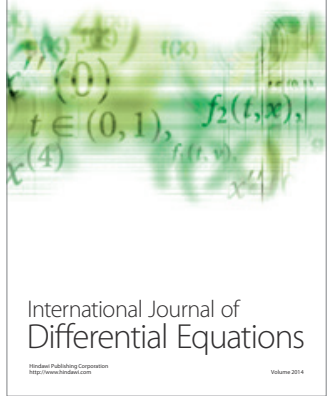
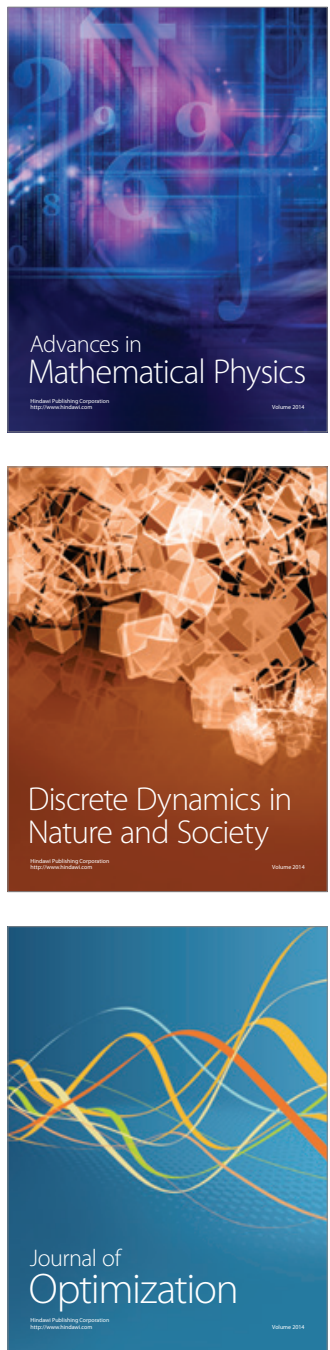